\title{
Torque Analysis on a Double Rotor Electrical Variable Transmission With Hybrid Excitation
}

\author{
Joachim Druant, Hendrik Vansompel, Frederik De Belie, Member, IEEE, \\ Jan Melkebeek, Senior Member, IEEE, and Peter Sergeant, Member, IEEE
}

\begin{abstract}
An electrical variable transmission (EVT) can be used as a power splitting device in hybrid electrical vehicles. The EVT analyzed in this paper is a rotating field electrical machine having two concentric rotors. On the outer rotor, permanent magnets (PMs) are combined with a dcfield winding, being the first implementation of its kind. The magnetic field in the machine as well as the electromagnetic torque on both rotors are a function of the $q$ - and $d$-axis currents of the stator and inner rotor, as well as the dc-field current. To describe and fully understand this multiple-input multiple-output machine, this paper gives an overview of the influence of the different current inputs on the flux linkage and torque on both rotors. Focus is given to the hybrid excitation in the $d$-axis by combining the dc-field current and the alternating currents. This has the advantage compared to other EVT topologies that unwanted stator torque can be avoided without stator $d$-axis current flux weakening. Results of the analysis are presented by means of the torque to current characteristics of a double rotor PM-assisted EVT, as well as the torque to current ratios. The machine characteristics are finally experimentally verified on a prototype machine.
\end{abstract}

Index Terms-Electrical variable transmission (EVT), hybrid excitation, torque analysis.

\section{INTRODUCTION}

A $\mathrm{N}$ ELECTRICAL variable transmission (EVT) can be used in hybrid electrical vehicles (HEVs) to replace the planetary gear set and two electrical machines [1]. Topologically an EVT can be seen as a rotating field electrical machine with two concentric rotors. This is schematically shown in Fig. 1 for a vehicle with a longitudinal drive train. The two rotors are the two mechanical ports of the transmission. The machine is able to transmit power from the input to the output shaft in an electromagnetic way only, so without meshing gears or wetplate clutches as is the case in conventional transmissions [2]. Moreover, the gear ratio between the input shaft and the output shaft can be varied continuously. Hereby, most of the power is transmitted by the electromagnetic torque interaction between

Manuscript received April 22, 2016; revised May 25, 2016 and June 17, 2016; accepted July 14, 2016. Date of publication September 13, 2016; date of current version December 9, 2016. This work was supported by the Research Foundation-Flanders (FWO).

The authors are with the Electrical Energy Laboratory, Department of Electrical Energy, Systems and Automation, Ghent University, B-9000 Ghent, Belgium, and also with Flanders Make, 3920 Lommel, Belgium (e-mail: Joachim.Druant@Ugent.be; Hendrik.Vansompel@UGent.be; Frederik.DeBelie@UGent.be; jan.melkebeek@ugent.be; Peter. Sergeant@UGent.be).

Color versions of one or more of the figures in this paper are available online at http://ieeexplore.ieee.org.

Digital Object Identifier 10.1109/TIE.2016.2608768

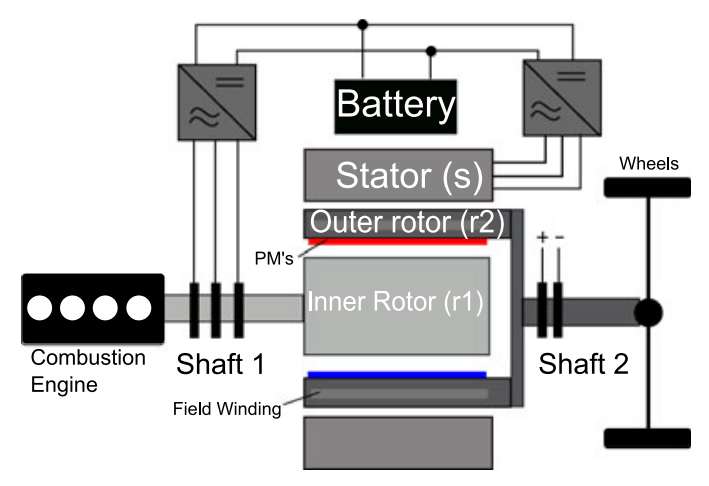

Fig. 1. Schematic of a single-layer PM EVT with dc-field winding used in an HEV.

the inner and the outer rotor. Depending on the speed difference, the remaining part of the power is transmitted in an electrical way and by the electromagnetic torque between the stator and the outer rotor. To this end, the transmission possesses two electrical ports, being the stator phase windings on the one hand, and the inner rotor phase windings and slip rings on the other hand. Two back to back inverters are used to control the inner and outer rotor currents, and thus, create a desired electromagnetic torque on both rotors. Optionally electrical storage can be added to the dc-bus in between the inverters, giving the EVT hybrid functionality.

Different EVT topologies have been proposed and analyzed in the literature. The authors of [3]-[5] describe the fundamental working principle of the induction-machine-based EVT. Here, the outer rotor consists of a squirrel cage, thus avoiding the need for permanent magnets (PMs). Also, the magnetic field is changed for field weakening and optimal torque control [6], [7]. Most publications, however, show EVT topologies with PM rotors tending to have higher power density. Within the PM versions, basically two types can be considered. In [8][11], a magnetic gear is used to provide the speed difference between input and output shaft. The advantages are high power density and the absence of slip rings. However, an additional electrical machine has to be added to the system to have the same functionality as an EVT [12]-[14]. Another type of EVT often described in the literature consists of a wound rotor with slip rings, a PM outer rotor and a stator [15]-[20]. The inner rotor and PM outer rotor basically account for the speed difference between input and output shaft, while the stator and outer rotor account for the difference in torque.

In all versions, the PM flux is fully coupled with stator and inner rotor. However, when analyzing the EVT for different 


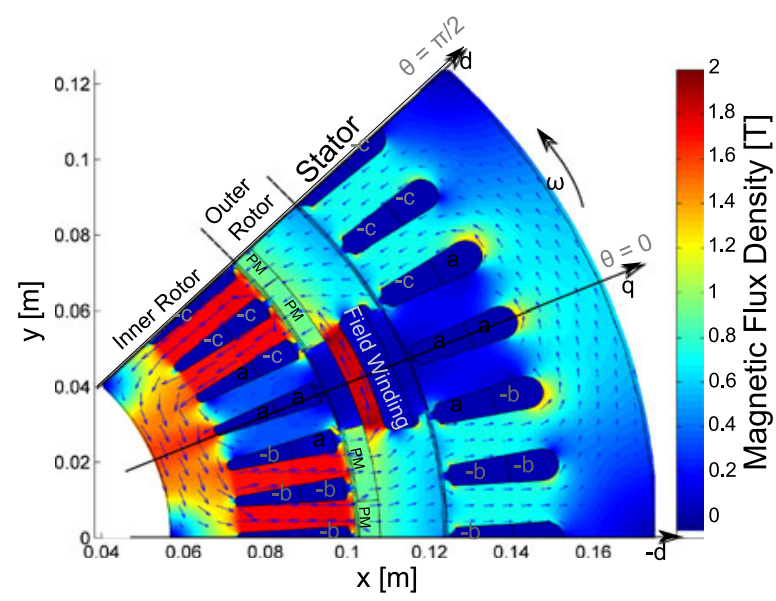

Fig. 2. Cross-sectional view of the EVT, showing the stator (index s), outer rotor (index r2), and inner rotor (index r1). All currents are zero.

driving cycles, the EVT stator torque is low most of the time [21], [22], being high only during acceleration and driving uphill. It is, thus, useful to be able to change the flux linkage with the stator. Moreover, a low flux linkage is required during longer time periods, while only at peak torque high flux levels are required. The machine described in this patent [23] is able to change the stator flux linkage, while maintaining the inner rotor flux linkage, being the first implementation of its kind. To this end, the machine possesses a dc-field winding, to be combined with stator windings. In order to describe and fully understand the PM-assisted EVT, an overview is given on the influence of the different current inputs upon the flux linkage and torque on both rotors. Focus is given to the hybrid excitation within the $d$-axis by combining the dc-field current and the alternating currents. Results of the analysis are presented by means of the torque to current characteristics of a double rotor PM-assisted EVT, as well as the optimal torque to current ratios. The machine characteristics are finally experimentally verified on a prototype machine.

\section{Influence of Field Excitation ON THE StATOR}

A cross-sectional view of the EVT topology considered in this paper is given in Fig. 2. Both the stator and the inner rotor consist of a distributed three-phase winding. The outer rotor is equipped with a single layer of PMs and a dc-field winding with flux bridge in between. The dc-field winding as well as $d$-axis stator and inner rotor currents can be used to create a desired flux linkage and torque on both rotors. This section gives a detailed overview of the stator flux linkage and the no-load characteristic of the machine. As will be shown, the no-load characteristic consists of three regions, each of those resulting in a specific torque to current behavior when a current torque component is supplied. Some machine parameters are given in Table I for clarity.

\section{A. PM Field}

The stator flux linkage determines the torque interaction between stator and outer rotor, which is called stator torque $\left(T_{s}\right)$ in
TABLE I

MACHINE PARAMETERS

\begin{tabular}{lccc}
\hline \hline & Stator & Outer Rotor & Inner Rotor \\
\hline Rated mechanical power [kW] & - & 120 & 75 \\
Rated current [A a m plitude $]$ & 265 & $4.6(\mathrm{DC})$ & 150 \\
Max speed [r/min] & - & 6000 & 6000 \\
Continuous torque [N.m] & 245 & 382 & 137 \\
Number of slots $N$ & 48 & - & 48 \\
Number of windings in series per pole & 48 & 240 & 40 \\
and per phase $w$ & & & \\
Number of parallel branches per phase & 4 & - & 4 \\
$a$ & & - & 4 \\
Number of slots per pole and per & 4 & 4 & 4 \\
phase $q$ & & 123.5 & 102 \\
Number of pole pairs $N_{p}$ & 4 & 103 & 57 \\
Outer radius [mm] & 175 & 5 & - \\
Inner radius [mm] & 124.5 & 87 & 87 \\
PM thickness [mm] & - & 5 & - \\
Active axial length [mm] & 87 & & \\
Width flux bridge [mm] & - & & \\
\hline
\end{tabular}

this paper. In no-load condition, the PMs are the only sources of magnetomotive force (MMF). The corresponding magnetic field is visualized in Fig. 2, along with the direct- and quadrature-axis. The PM flux shows a maximum in the air gap at the negative $d$-axis. Thus, any current flowing through a winding with axis along the positive $d$-axis causes weakening of the PM flux.

As mentioned before, most of the time the required stator torque is low. To this end, a flux bridge is present underneath the dc-field winding in Fig. 2. Due to the flux bridge, only part of the PM flux is linked with the stator, and hence, as the stator flux linkage is low, the corresponding torque is low as well. Note that by such a construction also the losses induced in the stator by the PM field are low. When a high stator torque is required during short times of acceleration or when driving up hill for longer time periods, either the dc-field current or the $d$ axis stator current can be used to increase the stator flux linkage as will be described in the next paragraphs.

\section{B. Influence of the DC-field current}

A negative dc-field current $I_{r 2 d}<0$ changes the PM flux path, and increases the magnetic flux linkage with the stator as visualized in Fig. 3. When increasing the dc-field current in absolute value, the flux bridge underneath the dc-field winding becomes magnetically linear, and more and more flux is linked with the stator. This is shown in Fig. 3(a) where the flux through the flux bridge is zero. If the dc-field current is increased even more, the stator yoke will saturate at high flux levels as in Fig. 3(b). Moreover, the flux bridge saturates again, having a flux density vector with opposite sense compared to the one in Fig. 2. The inner rotor field is almost not affected by the magnetic state of the bridge between the PMs and dc-field winding since magnets have a low recoil permeability of about 1.05 . However, there is some influence to be noted, as will be shown in Section III.

Fig. 4 shows the flux linkage of the stator and rotor $d$-axis flux $\Psi_{\mathrm{sd}}$ and $\Psi_{r 1 d}$ as function of this dc-field current. Also the flux through the outer rotor flux bridge $\Psi_{\mathrm{fb}}$ is shown. All flux 


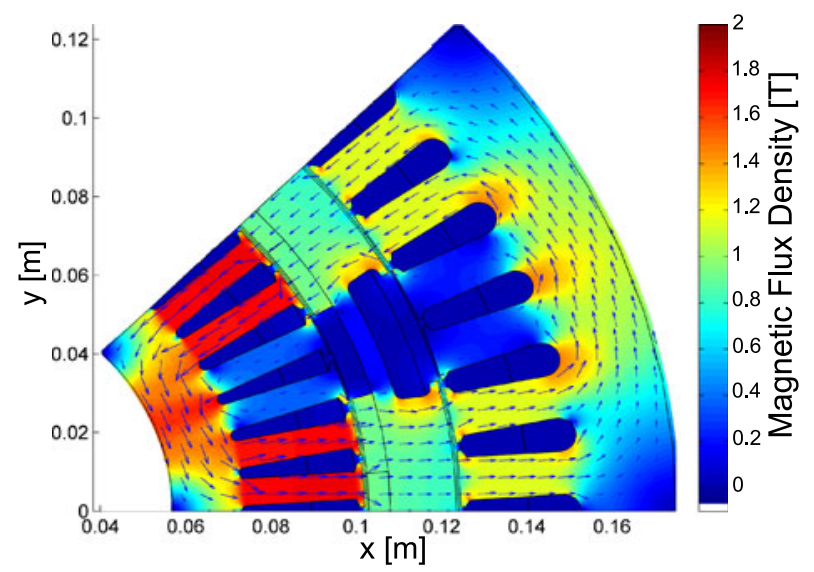

(a)

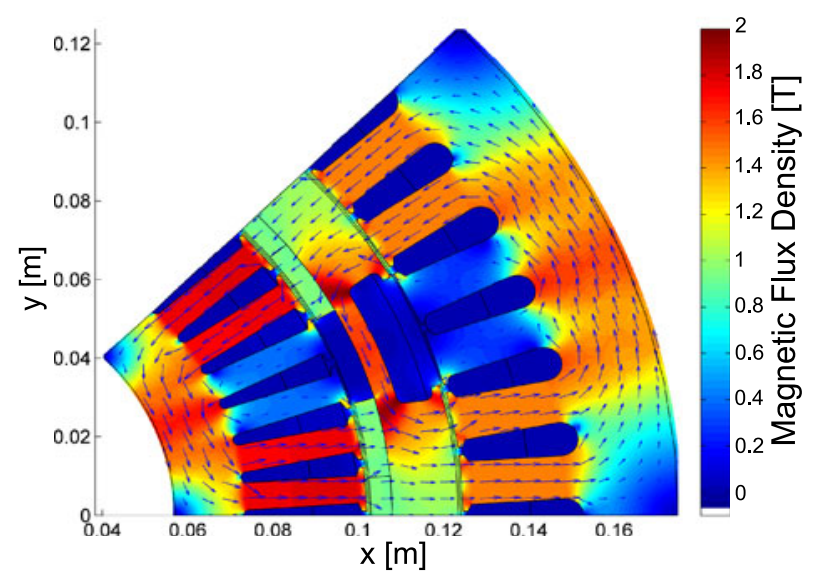

(b)

Fig. 3. Influence of the dc-field current $I_{r 2 d}$ on the stator flux linkage and bridge between PM material and dc-field winding. (a) $I_{r 2 d}=-6 \mathrm{~A}$; (b) $I_{r 2 d}=-10 \mathrm{~A}$.

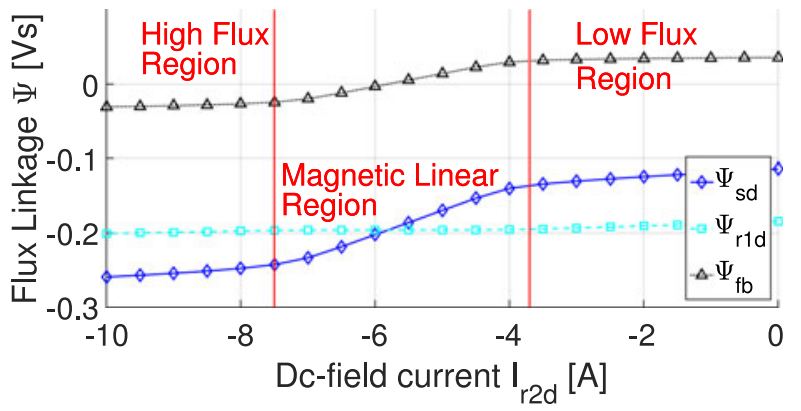

Fig. 4. FEM calculation of the no-load stator $d$-axis flux $\Psi_{\mathrm{sd}}$ and inner rotor $d$-axis flux $\Psi_{r 1 d}$ as function of excitation current $I_{r 2 d}$. Also the flux through the flux bridge $\Psi_{\mathrm{fb}}$ is shown.

linkages in this figure are referred to the stator by taking into account the number of windings.

As can be seen in the figure, three regions can be distinguished depending on the magnetic state of the flux bridge and the stator yoke. At zero dc-field current, the derivative of the stator flux linkage $\Psi_{\mathrm{sd}}$ with respect to the dc-field current $I_{r 2 d}$

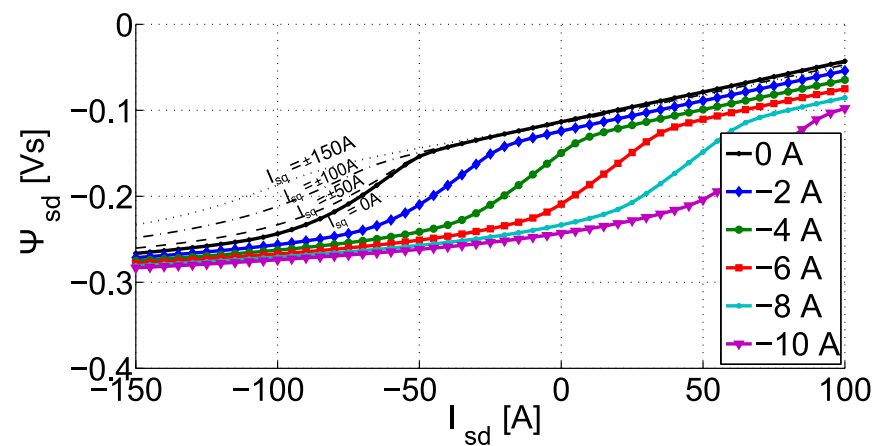

Fig. 5. FEM calculation of the stator $d$-axis flux $\Psi_{\mathrm{sd}}$ as function of stator $d$-axis current $I_{\mathrm{sd}}$ with dc-field current $I_{r 2 d}$ as parameter. The $q$ axis stator current $I_{\mathrm{sq}}$ is zero. The influence of $I_{\mathrm{sq}}$ is given for $I_{r 2 d}=0 \mathrm{~A}$ in dashed lines.

(tangential inductance) is low since the outer rotor flux bridge is heavily saturated as can also be seen in Fig. 2. This is called the low flux region of the no-load characteristic in this paper. As the dc-field current is lowered (increased in absolute value), the corresponding MMF in the bridge counteracts the MMF produced by the PMs and the bridge desaturates. This is the linear part of the iron BH curve, where an increase in dc-field current (in absolute value) has a big effect on the $d$-axis stator flux linkage. Finally, the stator yoke saturates, and the flux-current characteristic flattens out again forming the high flux region of the no-load curve. Using the dc-field current, it is thus possible to change the stator flux linkage, while maintaining the rotor flux linkage. Note that if the bridge flux $\Psi_{\mathrm{fb}}$ is zero, that the stator and inner rotor flux linkages are almost equal. This point has been marked on the figure. Finally, it can be seen that the inner rotor flux $\Psi_{r 1 d}$ is almost not influenced by the dc-field current as mentioned before. Since the torque between inner and outer rotor is equal to the internal combustion engine (ICE) torque in an HEV, a high flux level is indeed advised. Only at demagnetizing (positive) field currents, there is a small influence to be noticed.

\section{Influence of the Direct-Axis Stator Current}

The flux linkage with the stator can also be altered by a $d$-axis stator current $I_{\mathrm{sd}}$. This is shown in Fig. 5 for different dc-field currents $I_{r 2 d}$.

The shape of the stator $d$-axis flux $\Psi_{\mathrm{sd}}$ as function of the $d$-axis stator current resembles the one of Fig. 4. Again three regions can be distinguished. However, there are some differences to be mentioned. The stator windings are distributed in slots. Consequently, the spacial distribution of MMF produced by the stator current over the air gap will be more or less sinusoidal. The MMF over the air gap produced by the concentrated dc-field winding on the outer rotor is constant in between two slots, resulting in a square wave spacial MMF wave form, which is zero during $\frac{\pi}{3}$ electrical radians due to the dc-field winding itself. In order to compare both sources of stator $d$-axis flux, the linear part as described in the previous section is considered. In this part, both the stator and the outer rotor iron have a very 
high permeability so that the magnetic field strength $H$ is almost zero. Considering a field line linked with both the stator and the dc-field winding, Ampere's law can be used to give an idea of the magnetic field distribution in the air gap. In (1) and (2), the fundamental harmonics of the air gap magnetic field strength are given, produced by the stator and dc-field current, respectively,

$$
\begin{aligned}
H_{1}\left(I_{\mathrm{sd}}\right) & =\frac{3}{2} \frac{4}{\pi} \frac{\left(w_{1} \xi_{1}\right) \frac{I_{\mathrm{sd}}}{a}}{2 \delta}=\frac{3}{4 \pi \delta} w_{1} \xi_{1} I_{\mathrm{sd}} \\
H_{1}\left(I_{r 2 d}\right) & =\frac{4}{\pi} \cos \left(\frac{1}{2} \frac{\pi}{3}\right) \frac{w_{2} I_{r 2 d}}{2 \delta}=\frac{\sqrt{3}}{\pi \delta} w_{2} I_{r 2 d} .
\end{aligned}
$$

The winding distribution factor for the fundamental harmonic component is represented by $\xi_{1}$, whereas $\delta$ is the air gap width, and $a=4$ the number of parallel branches. The number of windings $w$ are given in Table I; see Section VI. The equations show that in order to produce the same fundamental harmonic air gap MMF, the ratio $r$ between the stator and dc-field current is given by

$$
r=\frac{I_{\mathrm{sd}}}{I_{r 2 d}}=\frac{4 \sqrt{3}}{3 \xi_{1}} \frac{w_{2}}{w_{1}}=12.4
$$

Indeed, if Figs. 4 and 5 are compared, the corresponding stator $d$-axis flux $\Psi_{\mathrm{sd}}$ can be referred to the outer rotor by using the ratio $r$. Also in Fig. 5, since $I_{r 2 d}$ is augmented with $2 \mathrm{~A}$ for every curve, the curves are horizontally shifted by $2 r=24.8 \mathrm{~A}$. The finite-element method (FEM) results thus show that this simple analysis can explain the equivalence of both current components. The comparison is accurate for the linear part, but still gives a good comparison if the flux bridge or the stator is saturated. It is thus the sum of $I_{\mathrm{sd}}$ and $r I_{r 2 d}$ that determines the flux linkage in Fig. 5. In this paper, $I_{\mathrm{sd} \text {,equiv }}=I_{\mathrm{sd}}+r I_{r 2 d}$ is called the equivalent $d$-axis current. If the copper losses are compared by using the resistances of Table I, it can be seen that the outer rotor resistor, referred to the stator, $R_{2}^{\prime}$ is

$$
R_{2}^{\prime}=\frac{R_{2}}{r^{2}}
$$

For this specific case, this is $\frac{12.73 \Omega}{r^{2}}=0.083 \Omega$, or 4.28 times higher than the stator resistance. To conclude, in order to reach a specific flux level at zero $q$-axis current, the optimal MMF distribution of the three-phase stator $d$-axis winding to dc-field winding is $\frac{4.28}{\frac{3}{2}}=2.85$ to 1 for this specific machine, since this ratio minimizes the copper losses in the $d$-axis winding

$$
P_{\mathrm{cu}}=\frac{3}{2} R_{s} I_{\mathrm{sd}}^{2}+R_{r 2} I_{r 2 d}^{2}
$$

with the constraint that $I_{1 d}+r I_{r 2 d}$ is a given set value. However, the stator $d$-axis current and dc-field current have a different influence on the stator torque, as will be shown in Section IV.

\section{Influence of the Quadrature Axis Stator Current}

As seen in the previous sections, the $d$-axis stator flux $\Psi_{\text {sd }}$ is a function of stator $d$-axis current $I_{\mathrm{sd}}$ and the dc-field current $I_{r 2 d}$. The cross effect of the $q$-axis stator current $I_{\mathrm{sq}}$ on the $d$ axis stator flux is a second-order effect, as is also shown in Fig. 5 in dashed lines. High (absolute value) $q$-axis currents saturate the stator yoke, resulting in the modified curves.

\section{E. Influence of Rotor Current Along the d-Axis}

The inner and outer rotor are separated by PMs, having a relative permeability of 1.05 . If the flux bridge is heavily saturated, some interference between stator flux and rotor current can be noticed, although very small. The FEM shows that the stator flux amplitude decreases about $2 \%$ with an increase in the $d$-axis rotor current $I_{r 1 d}$ of $10 \mathrm{~A}$. If the flux bridge is desaturated (in the linear region), the influence is negligible as can be expected. Therefore, the influence of the $d$-axis inner rotor current on the stator field will not be discussed further.

\section{INNER ROTOR MAGNetIC FIELD}

The inner rotor field determines the torque on the input shaft (inner rotor). The field is mainly decoupled from the stator field due to the PMs and air gap in between inner and outer rotor. Furthermore, as was shown in the no-load curve of Fig. 4, the influence of the negative dc-field current on the flux linkage with the rotor is very small. The same is true for a negative (flux enhancing) stator $d$-axis current. If on the other hand, a positive (flux weakening) stator $d$-axis current is applied, an effect on the rotor flux linkage can be seen since this current desaturates the rotor yoke. However, due to the decoupling effect of the PMs, the effect is of less importance to the operation of the machine. The FEM shows that the variation in rotor flux amplitude is negligible for a negative equivalent $d$-axis stator current $I_{\text {sd, equiv }}$, and decreases by about $1.7 \%$ for an increase of $10 \mathrm{~A}$ in an equivalent positive stator $d$-axis current.

\section{iV. Electromagnetic Torque}

The flux analysis allows to predict the behavior of the stator and inner rotor torque $T_{s}$ and $T_{r 1}$ for different currents. The inner rotor torque loads the ICE, while the sum of stator and inner rotor torque is equal to the outer rotor torque $T_{r 2}$ driving the wheels. From the classic machine theory, the electromagnetic torque on stator, outer and inner rotor can be written as

$$
\begin{aligned}
T_{s} & =\frac{3}{2} N_{p}\left(\Psi_{\mathrm{sq}} I_{\mathrm{sd}}-\Psi_{\mathrm{sd}} I_{\mathrm{sq}}\right) \\
T_{r 2} & =-\left(T_{s}+T_{r 1}\right) \\
T_{r 1} & =\frac{3}{2} N_{p}\left(\Psi_{r 1 q} I_{r 1 d}-\Psi_{r 1 d} I_{r 1 q}\right) .
\end{aligned}
$$

The equations show that there are two torque interactions resulting in the net stator torque. The $q$-axis current interacts with the $d$-axis flux and vice versa. It can thus be seen that although the stator $d$-axis current $I_{\mathrm{sd}}$ and the dc-field current $I_{r 2 d}$ have a similar effect on the stator $d$-axis flux linkage $\Psi_{\text {sd }}$, the effect on the torque is different. In (5), the first term only considers the stator $d$-axis current $I_{\mathrm{sd}}$, not the dc-field winding $d$ axis current $I_{r 2 d}$. The second term considers the total $d$-axis flux $\Psi_{\mathrm{sd}}$, produced by both the PMs, $I_{\mathrm{sd}}$ and $I_{r 2 d}$. In the following, the influence of each of the currents on the torque generation will be discussed. 


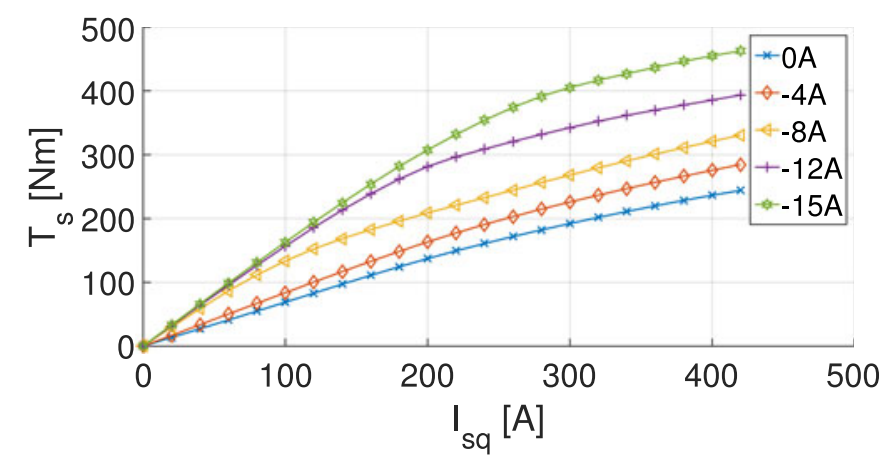

Fig. 6. Stator torque $T_{s}$ as function of stator $q$-axis current $I_{\mathrm{sq}}$ for different field currents $I_{r 2 d}$.

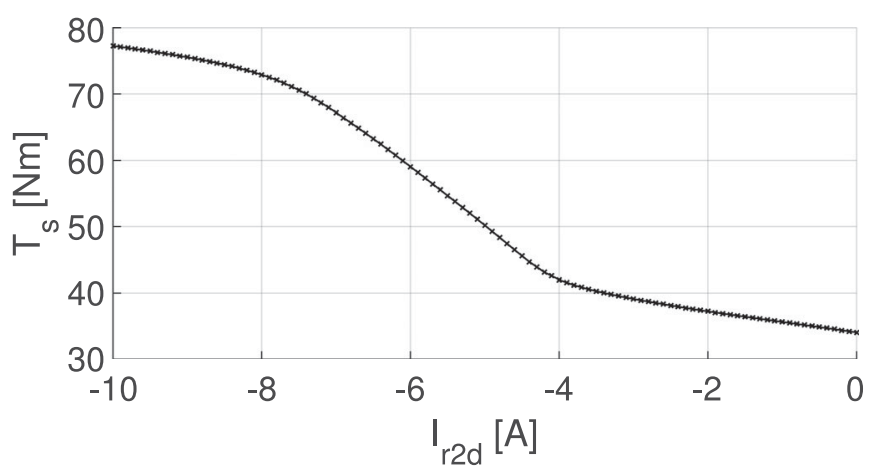

Fig. 7. Stator torque $T_{s}$ as function of dc-field current $I_{r 2 d}$ for a stator $q$-axis current $I_{\mathrm{sq}}$ of $50 \mathrm{~A}$. The stator $d$-axis current $I_{\mathrm{sd}}$ is zero.

\section{A. Influence of the DC-Field Current}

If no $d$-axis stator current is present, the machine behaves as a conventional synchronous machine as function of the stator $q$-axis $I_{\mathrm{sq}}$ and the dc-field current $I_{r 2 d}$. The torque as function of the $q$-axis stator current is shown in Fig. 6 for different field currents $I_{r 2 d}$. Note that there is substantial cross linkage between $d$ - and $q$-axis at high stator and dc-field currents.

Fig. 7 shows the evolution of the torque for a fixed stator $q$-axis current $I_{\mathrm{sq}}$. In case of the zero dc-field current, the stator torque is low, as was explained previously. If a higher torque is needed, a negative dc-field current can be injected as can be seen. Also note that the three regions of the no-load curve of Fig. 4 are clearly visible. A negative dc-field current increases the $d$-axis stator flux amplitude, and thus, the stator torque. In agreement with Fig. 4, the variation with the dc-field current is highest for currents between -4 and $-8 \mathrm{~A}$, corresponding with the magnetic linear part of the no-load curve.

\section{B. Influence of the Direct-Axis Stator Current}

The stator $d$-axis current influences both terms in the stator torque equation

$$
T_{s}=\underbrace{\frac{3}{2} N_{p} \Psi_{\mathrm{sq}} I_{\mathrm{sd}}}_{T_{\mathrm{qd}}} \underbrace{-\frac{3}{2} N_{p} \Psi_{\mathrm{sd}} I_{\mathrm{sq}}}_{T_{\mathrm{dq}}} .
$$

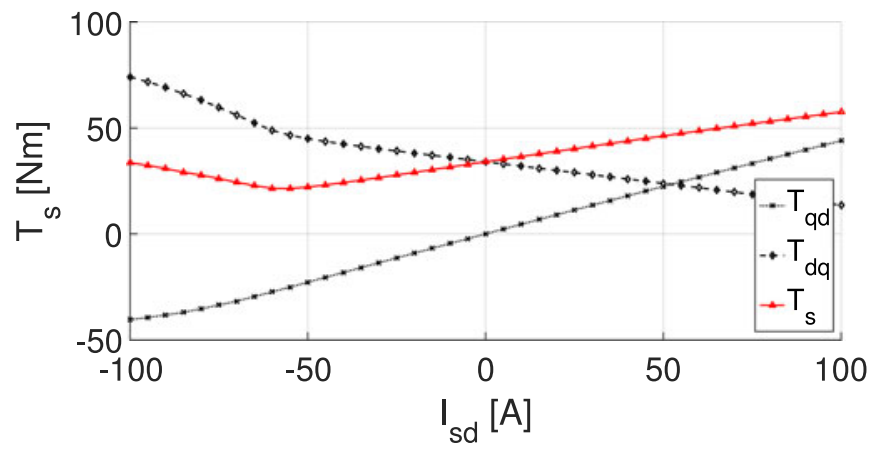

Fig. 8. Torque components and net stator torque as function of stator $d$-axis current $I_{\mathrm{sd}}$ for a stator $q$-axis current $I_{\mathrm{sq}}$ of $50 \mathrm{~A}$. The dc-field current $I_{r 2 d}$ is zero.

Both torque components of (9) as well as the resulting stator torque are represented in Fig. 8 as function of the $d$-axis current.

In the case of a salient pole synchronous machine, the torque would increase toward negative (flux enhancing) $d$-axis currents . The last term of (6) is hereby increased, while the first term remains approximately zero since there is no $q$-axis flux. The resulting curve $T_{\mathrm{dq}}=-\frac{3}{2} N_{p}\left(\Psi_{\mathrm{sd}} I_{\mathrm{sq}}\right)$ is shown in Fig. 8. At $I_{\mathrm{sd}}<-50 \mathrm{~A}$, the torque increases more than linearly in agreement with Fig. 5. Moreover, this latter torque characteristic has the same evolution as in Fig. 7 if an equivalent dc-field current $I_{\text {sd,equiv }}$ is considered $(r=12.4)$. However, in contrast to the dcfield current $I_{r 2 d}$, the stator $d$-axis current $I_{\mathrm{sd}}$ also interacts with the stator $q$-axis flux $\Psi_{\mathrm{sq}}$. Due to the specific geometry, the $q$ axis flux is not zero. This torque interaction is the second torque component $T_{\mathrm{qd}}=\frac{3}{2} N_{p}\left(\Psi_{\mathrm{sq}} I_{\mathrm{sd}}\right)$ in Fig. 8. By comparing the slope (derivative) of both torque components, the evolution of the total stator torque $T_{s}$ as function of the stator $d$-axis current $I_{\text {sd }}$ can be explained

$$
\begin{aligned}
& \frac{\mathrm{d}}{\mathrm{d} I_{\mathrm{sd}}}\left(T_{\mathrm{qd}}\right)=\frac{3}{2} N_{p}\left(I_{\mathrm{sd}} \frac{\mathrm{d}}{\mathrm{d} I_{\mathrm{sd}}}\left(\Psi_{\mathrm{sq}}\right)+\Psi_{\mathrm{sq}}\right) \\
& \frac{\mathrm{d}}{\mathrm{d} I_{\mathrm{sd}}}\left(T_{\mathrm{dq}}\right)=-\frac{3}{2} N_{p}\left(I_{\mathrm{sq}} \frac{\mathrm{d}}{\mathrm{d} I_{\mathrm{sd}}}\left(\Psi_{\mathrm{sd}}\right)\right) .
\end{aligned}
$$

Considering (10), the influence of the $d$-axis stator current $I_{\mathrm{sd}}$ on the $q$-axis stator flux $\Psi_{\mathrm{sq}}$ is only of importance at strongly negative equivalent $d$-axis currents $I_{\text {sd,equiv. }}$. By neglecting this term, the derivative of the total stator torque $T_{s}=T_{\mathrm{qd}}+T_{\mathrm{dq}}$ can thus be written as

$$
\frac{d}{d I_{\mathrm{sd}}}\left(T_{1}\right)=\frac{3}{2} N_{p}\left(\left(L_{q}^{c}-L_{d}^{t}\right) I_{\mathrm{sq}}\right)
$$

with

$$
\left\{\begin{array}{l}
L_{q}^{c}=\frac{\Psi_{\mathrm{sq}}}{I_{\mathrm{sq}}} \\
L_{d}^{t}=\frac{d \Psi_{\mathrm{sd}}}{d I_{\mathrm{sd}}}
\end{array}\right.
$$

chord slope inductance along the $q$-axis and the tangential inductance along the $d$-axis, respectively. The torque, thus, increases with the stator $d$-axis current $I_{\mathrm{sd}}$ if $L_{q}^{c}>L_{d}^{t}$. As can be seen in Fig. $8, \frac{d T_{1}}{d I_{\mathrm{sd}}}$ changes sign if the $d$-axis magnetic state enters the linear part as described in Fig. 5. 


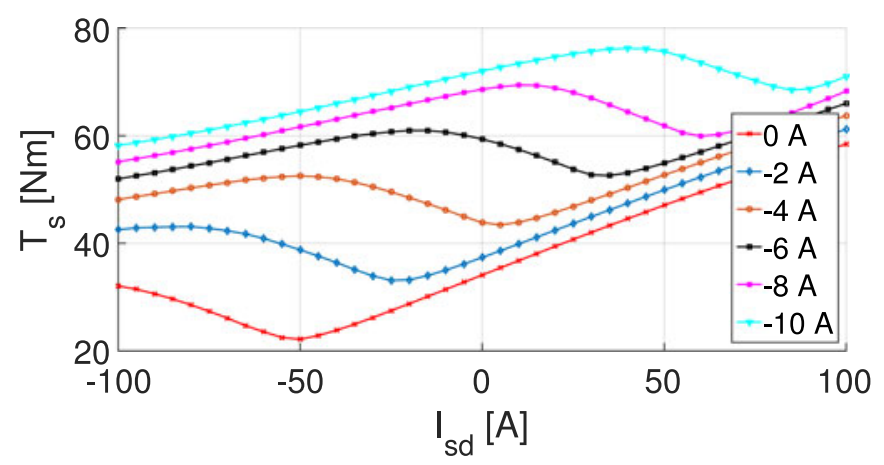

Fig. 9. Stator torque as function of stator $d$-axis current $I_{\mathrm{sd}}$ for a stator $q$-axis current $I_{\mathrm{sq}}$ of $50 \mathrm{~A}$ for different field currents $I_{r 2 d}$.

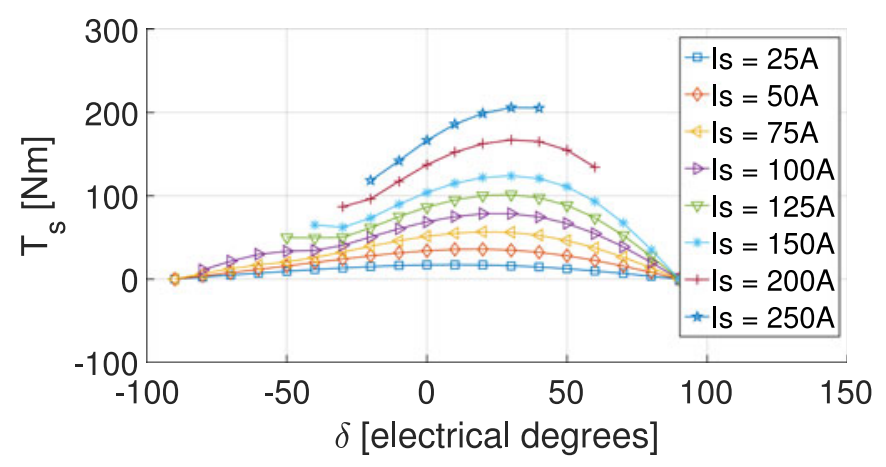

Fig. 10. Stator torque $T_{s}$ as function of stator current magnitude and phase. DC-field current $I_{r 2 d}=0 \mathrm{~A}$.

Only in this region, the tangential $d$-axis inductance $L_{d}^{t}$ is higher than the chord $q$-axis inductance $L_{q}^{c}$. In accordance with Fig. 5, the magnetic linear region shifts toward higher $d$-axis stator currents if a dc-field current $I_{r 2 d}$ is applied. This finally explains the torque function for different field currents as given in Fig. 9, each with its local maximum and minimum.

\section{TORQUE-TO-CURRENT RATIO}

The aforementioned analysis shows that both the stator $d$-axis current and the dc-field current can be used to modulate the stator flux linkage. However, the stator $d$-axis current also interacts with the stator $q$-axis flux linkage, and thus, has another effect on the torque. In the machine theory, it is more convenient to show the torque as function of the current magnitude and phase. This is another way of representing the torque-to-current relationship described thus far. The EVT considered has two shafts, and five current components making it difficult to present these results in a 2-D graph. However, since both rotors are mainly decoupled, it is possible to show the stator torque as function of the stator and dc-field current. This is shown for different field currents in Figs. 10-12. The extra degree of freedom of the dc-field current can be used to minimize the losses for a given torque and speed of both rotors.

\section{EXPERIMENTAL VERIFICATION}

In order to experimentally verify the statements made previously, a test setup has been constructed. The setup is shown in Fig. 13. Two induction motors have been coupled to both shafts

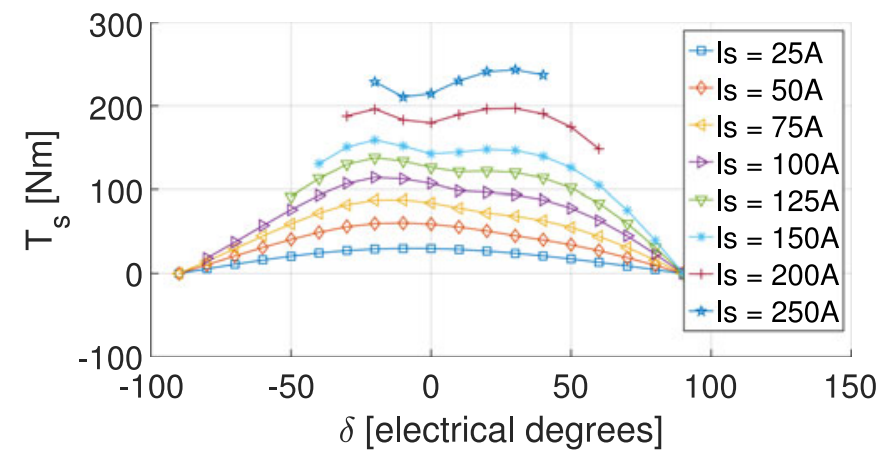

Fig. 11. Stator torque $T_{s}$ as function of stator current magnitude and phase. DC-field current $I_{r 2 d}=-6 \mathrm{~A}$.

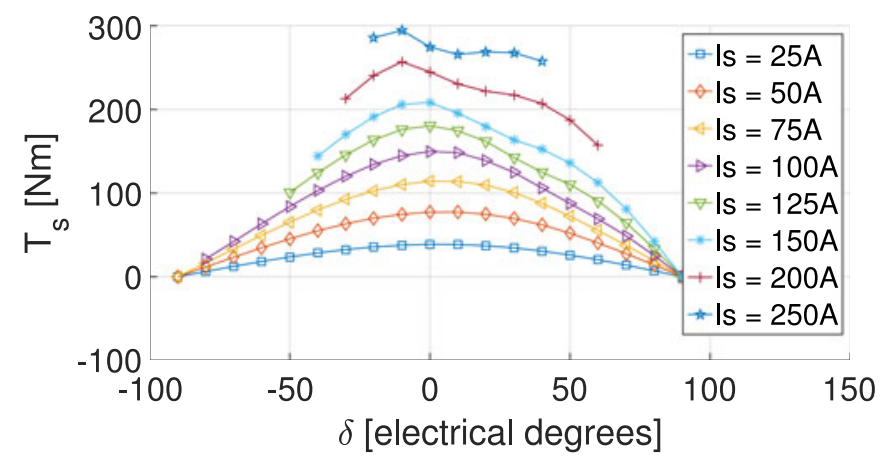

Fig. 12. Stator torque $T_{s}$ as function of stator current magnitude and phase. DC-field current $I_{r 2 d}=-10 \mathrm{~A}$.

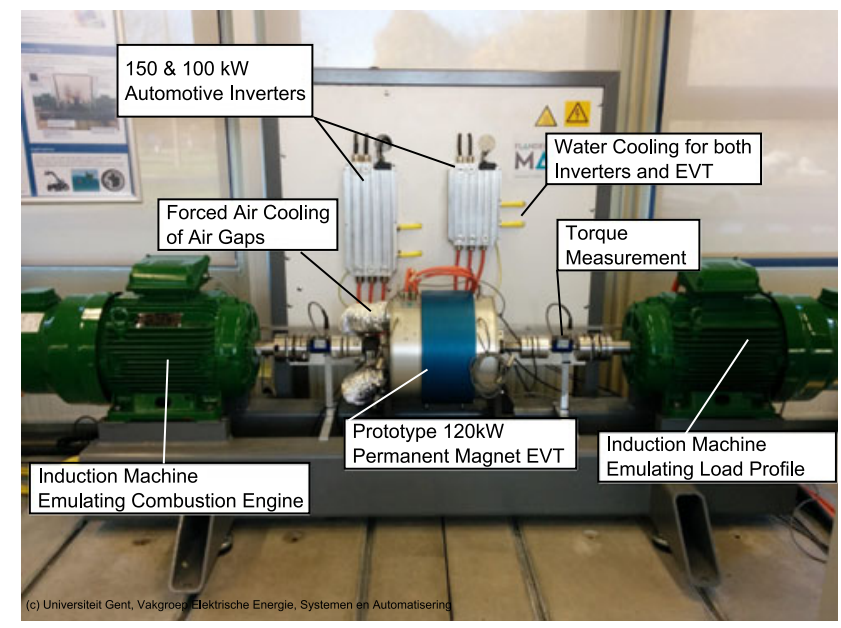

Fig. 13. Experimental setup.

of the EVT. In between, torque transducers have been placed. Some parameters of the EVT in the setup were given in Table I. Also note that the stator possesses a water jacket for cooling and that forced air cooling of the air gaps is provided. The rated currents can be seen in the table. A detailed thermal analysis is, however, out of the scope of this paper, which is about the electromagnetic analysis.

\section{A. No-Load Characteristic}

Fig. 14 shows the verification of the no-load characteristic of Fig. 4. To this end, the outer rotor was driven at $400 \mathrm{r} / \mathrm{min}$ 


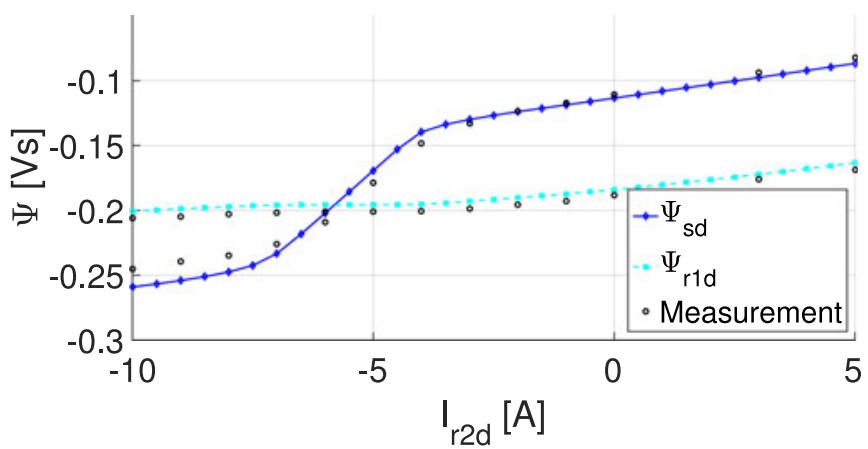

Fig. 14. Measurement of the stator $d$-axis flux $\Psi_{\mathrm{sd}}$ as function of excitation current $I_{r 2 d}$.

by one of the induction motors, while the inner rotor was held stationary. This way both the stator and rotor are subjected to a magnetic field with the same frequency. By measuring the voltage at the machine terminals at no-load, the flux linkage could be calculated. The figure shows good agreement between FEM calculations and experimental results. It also confirms that the electromagnetic coupling between stator and inner rotor is low. Except for demagnetizing $(>0) d$-axis currents, the influence of the dc-field current $I_{r 2 d}$ on the inner rotor flux $\Psi_{r 1 d}$ is small as shown before.

\section{B. Stator Torque}

The stator torque has been verified using a torque sensor placed between the outer rotor and an induction machine. Set values for the $q$ - and $d$-axis stator currents can be sent to the $150-\mathrm{kW}$ inverter feeding the stator. A separate current regulated dc power supply (not shown in Fig. 13) has been used to feed the outer rotor dc-field winding. A power analyzer is used to compare the actual applied currents with the set values given to the inverters and power supply. The torque sensors have a given accuracy of $0.1 \%$ and are limited to $100 \mathrm{~N} \cdot \mathrm{m}$, so only this torque range has been measured. For every point, the torque has been measured over a 10-s time range, and averaged to account for measurement noise. Also a torque offset in the order of $1-3 \mathrm{~N} \cdot \mathrm{m}$ is expected due to the drag force of the slip rings and the bearings.

Fig. 15 shows the stator torque as function of the $q$-axis stator current $I_{\mathrm{sq}}$ for different field currents $I_{r 2 d}$ to be compared with Fig. 6. Despite the aforementioned difficulties, FEM and experimental data show a very good agreement. The stator torque $T_{s}$ as function of the de-field current $I_{r 2 d}$ is shown in Fig. 16. The measurements confirm that the stator torque can be modulated accurately using the dc-field current. It also confirms the position of the three magnetic regions as function of the dccurrent, in accordance with Fig. 14 where the measured no-load curve is plotted. Fig. 17 finally confirms the torque analysis of Section IV-B in which the stator torque was considered for different $d$-axis currents. In the latter figure, the deviation from the theoretical expected values is a little higher, showing that the $d$-axis saturates more than expected under $d$-axis stator current. However, the maximum and minimum in stator torque as func-

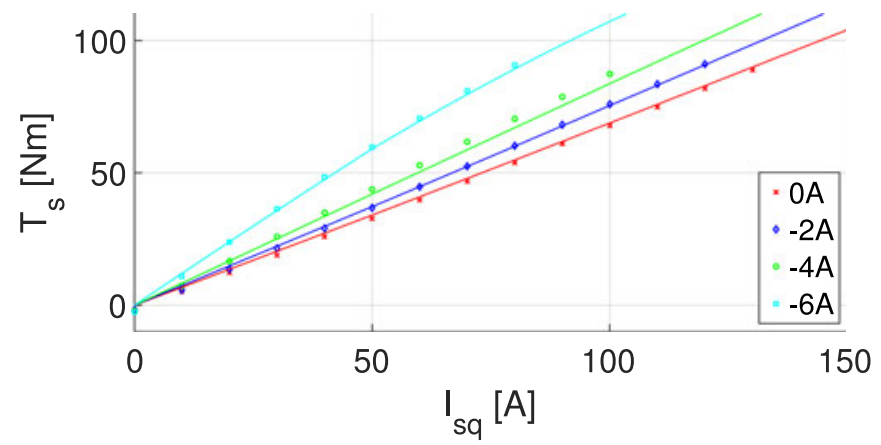

Fig. 15. Measurement of the stator torque as function of $q$-axis stator current $I_{\mathrm{sq}}$ for different field currents $I_{r 2 d} . I_{\mathrm{sd}}=0 \mathrm{~A}$. The solid lines denote FEM predictions.

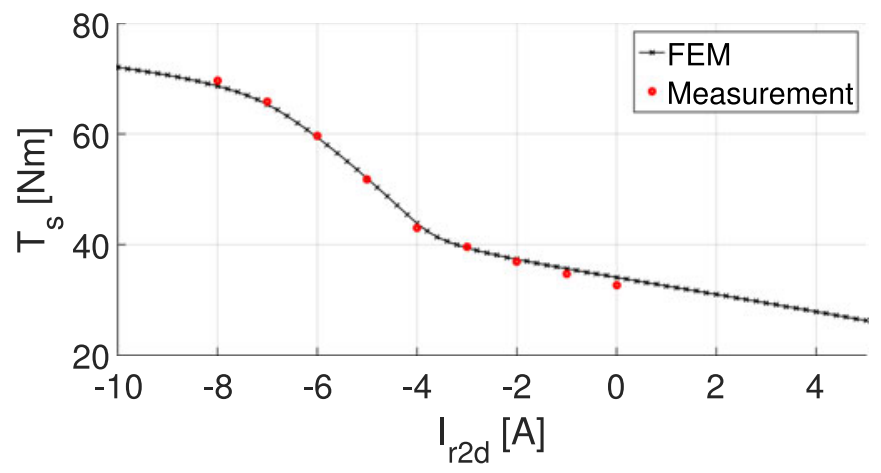

Fig. 16. Measurement of the stator torque as function of dc-field current $I_{r 2 d}$. Stator currents: $I_{\mathrm{sq}}=50 \mathrm{~A}$, stator $d$-axis current $I_{\mathrm{sd}}=0 \mathrm{~A}$.

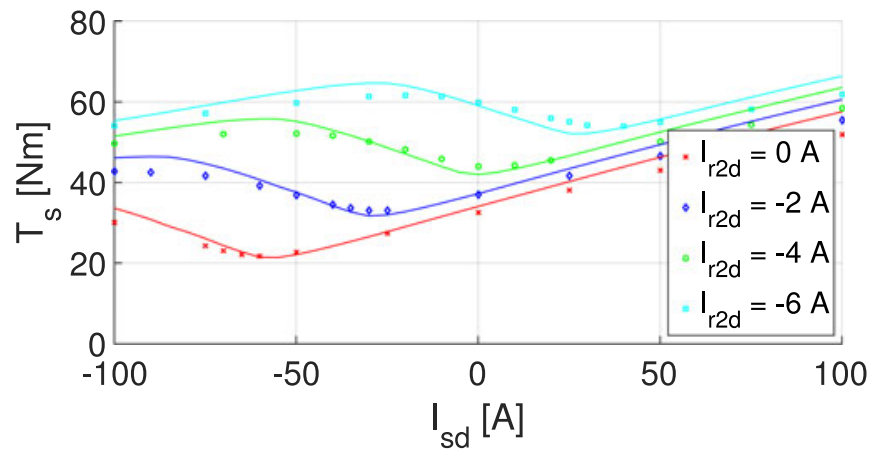

Fig. 17. Measurement of the stator torque as function of $d$-axis stator current $I_{\mathrm{sd}}$. Stator $q$-axis current $I_{\mathrm{sq}}=50 \mathrm{~A}$. In solid lines, the corresponding theoretical (FEM) results are given.

tion of the stator $d$-axis current are clearly visible, separating the three different regions as declared before

\section{Rotor Torque}

Finally, the torque on the inner rotor has been experimentally verified. Set values for the rotor current where given to the $100-\mathrm{kW}$ inverter, and where verified by an external current measurement. As can be seen from Fig. 18, the FEM again accurately describes the machine. The rotor torque was measured for different $d$-axis stator currents, confirming the weak coupling between both rotors as analyzed in Section III. 


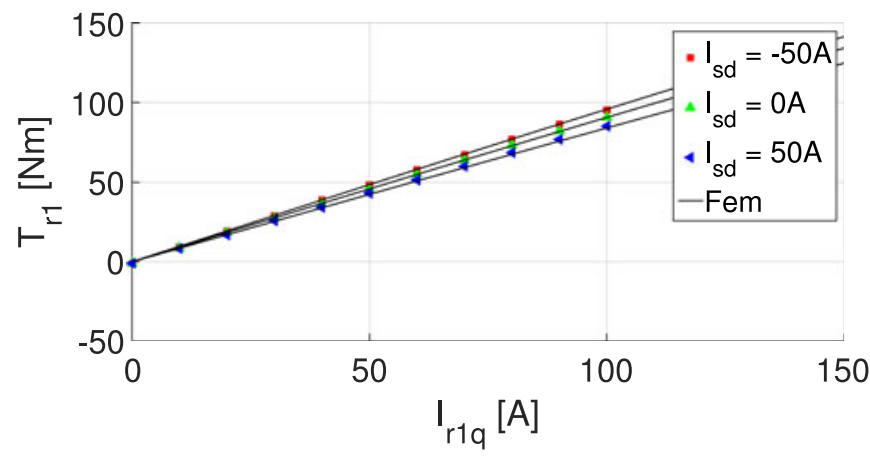

Fig. 18. Measurement of rotor torque as function of $q$-axis rotor current $I_{r 1 q}$ for different $d$-axis stator currents. In solid lines, the corresponding theoretical (FEM) results are given.

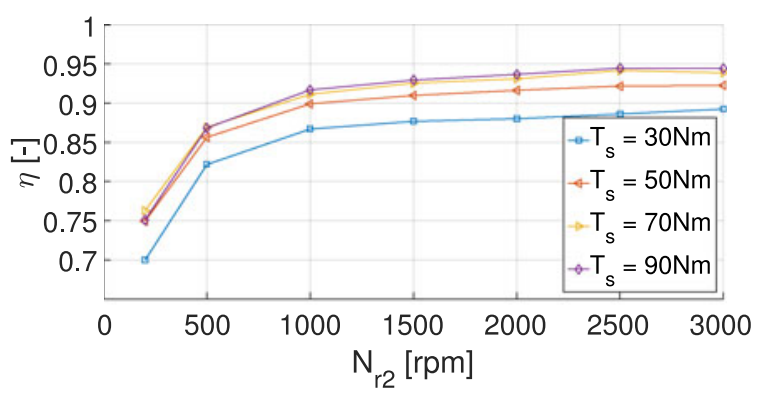

(a)

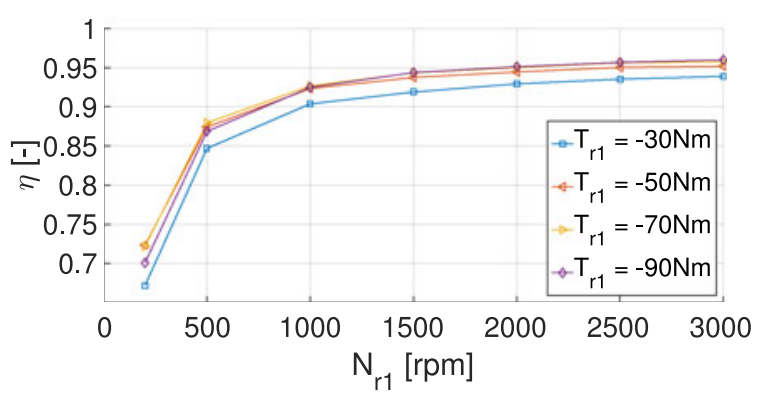

(b)

Fig. 19. Efficiency measurements in some operating points. (a) Stator - Outer Rotor; (b) Inner Rotor - Outer Rotor.

\section{Efficiency}

To give an idea about the efficiency of this machine, two experiments have been conducted as can be seen in Fig. 19. During the first set of measurements, the inner rotor was at stand-still and no current was applied, whereas the stator speed and current were varied. A combination of stator $q$ - and $d$ axis currents and dc-field current was used. During the second experiment, the stator currents and outer rotor speed were zero. The inner rotor speed and $q$-axis current were varied.

\section{CONCLUSION}

A detailed analysis of the magnetic field distribution in a double rotor PM machine with hybrid excitation has been performed. This paper showed the influence of the five independent current components on the flux linkage with stator and inner rotor. The effects were clearly subdivided according to their effect on the magnetic field and the torque. The $d$-axis stator field was weakened by the presence of the flux bridge, short circuiting part of the PM rotor flux. The modulation was performed by controlling both the dc-field current and $d$-axis stator current. Although both components have a similar effect on the field generation along the $d$-axis, the effect on the torque is different as besides the $d$-axis stator current, the $d$-axis stator flux influences the torque as well. As a result, the stator torque shows a minimum and maximum as function of the $d$-axis stator current. As for the dc-field current, the machine behaves like a synchronous machine with salient poles. The effect of cross coupling with the $q$-axis and with the inner rotor was shown to be present, although the influence was small. It was shown that the inner rotor field and torque are only slightly influenced by the stator and field currents, except for highly demagnetizing currents. Finally, the optimal torque to current lines were given for different dc-field currents. The dc-field winding on the outer rotor gives an additional degree of freedom to minimize the losses compared to an EVT without field winding.

\section{ACKNOWLEDGMENT}

The authors would like to thank the company EVT BV for designing and building the prototype PM EVT machine.

\section{REFERENCES}

[1] L. Xu, Y. Zhang, and X. Wen, "Multioperational modes and control strategies of dual-mechanical-port machine for hybrid electrical vehicles," IEEE Trans. Ind. Appl., vol. 45, no. 2, pp. 747-755, Mar./Apr. 2009.

[2] M. A. Kluger and D. M. Long, "An overview of current automatic, manual and continuously variable transmission efficiencies and their projected future improvements," SAE Technical Paper, 1999.

[3] M. Hoeijmakers and J. Ferreira, "The electric variable transmission," IEEE Trans. Ind. Appl., vol. 42, no. 4, pp. 1092-1100, Jul./Aug. 2006.

[4] M. Hoeijmakers, "Electromechanical converter," U.S. Patent 7164219 , Jan. 16, 2007.

[5] H. Cai and L. Xu, "Modeling and control for cage rotor dual mechanical port electric machine-Part I: Model development," IEEE Trans. Energy Convers., vol. 30, no. 3, pp. 957-965, Sep. 2015.

[6] J. Druant, F. D. Belie, P. Sergeant, and J. Melkebeek, "Field-oriented control for an induction-machine-based electrical variable transmission," IEEE Trans. Veh. Technol., vol. 65, no. 6, pp. 4230-4240, Jun. 2016.

[7] H. Cai and L. Xu, "Modeling and control for cage rotor dual mechanical port electric machine-Part II: Independent control of two rotors," IEEE Trans. Energy Convers., vol. 30, no. 3, pp. 966-973, Sep. 2015.

[8] K. Atallah, J. Wang, S. Calverley, and S. Duggan, "Design and operation of a magnetic continuously variable transmission," IEEE Trans. Ind. Appl., vol. 48, no. 4, pp. 1288-1295, Jul./Aug. 2012.

[9] T. V. Frandsen et al., "Motor integrated permanent magnet gear in a battery electrical vehicle," IEEE Trans. Ind. Appl., vol. 51, no. 2, pp. 1516-1525, Mar./Apr. 2015.

[10] J. Bai et al., "A new magnetic-field-modulated brushless double-rotor machine," IEEE Trans. Magn., vol. 51, no. 11, pp. 1-4, Nov. 2015.

[11] L. Sun, M. Cheng, and H. Jia, "Analysis of a novel magnetic-geared dualrotor motor with complementary structure," IEEE Trans. Ind. Electron., vol. 62, no. 11, pp. 6737-6747, Nov. 2015.

[12] K. Atallah and D. Howe, "A novel high-performance magnetic gear," IEEE Trans. Magn., vol. 37, no. 4, pp. 2844-2846, Jul. 2001.

[13] L. Jian and K. Chau, "Design and analysis of a magnetic-geared electroniccontinuously variable transmission system using finite element method," Progress Electromagn. Res., vol. 107, pp. 47-61, 2010.

[14] J. Bai, P. Zheng, C. Tong, Z. Song, and Q. Zhao, "Characteristic analysis and verification of the magnetic-field-modulated brushless double-rotor machine," IEEE Trans. Ind. Electron., vol. 62, no. 7, pp. 4023-4033, Jul. 2015.

[15] P. Pisek, B. Stumberger, T. Marcic, and P. Virtic, "Design analysis and experimental validation of a double rotor synchronous PM machine used for HEV," IEEE Trans. Magn., vol. 49, no. 1, pp. 152-155, Jan. 2013. 
[16] X. Sun and M. Cheng, "Thermal analysis and cooling system design of dual mechanical port machine for wind power application," IEEE Trans. Ind. Electron., vol. 60, no. 5, pp. 1724-1733, May 2013.

[17] Y. Zhu, M. Cheng, W. Hua, and B. Zhang, "Sensorless control strategy of electrical variable transmission machines for wind energy conversion systems," IEEE Trans. Magn., vol. 49, no. 7, pp. 3383-3386, Jul. 2013.

[18] E. Nordlund and C. Sadarangani, "The four-quadrant energy transducer," in Proc. 37th IEEE Ind Appl. Soc. Аnnu. Meet., vol. 1, Oct. 2002, pp. 390-397.

[19] Y. Liu et al., "Magnetic system study of a compound-structure permanentmagnet synchronous machine for HEVs," IEEE Trans. Ind. Appl., vol. 48, no. 6, pp. 1797-1807, Nov./Dec. 2012.

[20] X. Sun and M. Cheng, "Thermal analysis and cooling system design of dual mechanical port machine for wind power application," IEEE Trans. Ind. Electron., vol. 60, no. 5, pp. 1724-1733, May 2013.

[21] Y. Cheng, R. Trigui, C. Espanet, A. Bouscayrol, and S. Cui, "Specifications and design of a pm electric variable transmission for Toyota Prius II," IEEE Trans. Veh. Technol., vol. 60, no. 9, pp. 4106-4114, Nov. 2011.

[22] E. Vinot et al., "Improvement of an EVT-based HEV using dynamic programming," IEEE Trans. Veh. Technol., vol. 63, no. 1, pp. 40-50, Jan. 2014

[23] M. Hoeijmakers, "Rotating electromechanical converter," U.S. Patent 9018 863, Apr. 28, 2015.

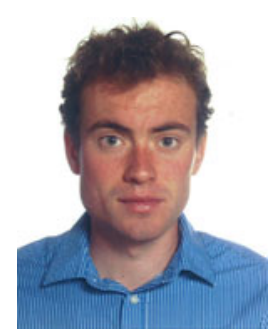

Joachim Druant was born in Belgium in 1990. He received the M.Sc. degree in electromechanical engineering in 2013 from Ghent University, Ghent, Belgium. In 2014, he received a Ph.D. Fellowship from the Research FoundationFlanders, and is currently working toward the Ph.D. degree in the Electrical Energy Laboratory, Department of Electrical Energy, Systems and Automation, Ghent University.

His present research interests include digital control of converter-fed electrical machines, fault-tolerant control, and modeling and control of electrical variable transmissions.

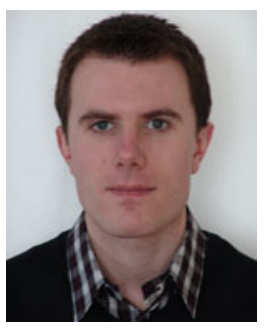

Hendrik Vansompel was born in Belgium in 1986. He received the Master's and Ph.D. degrees in electromechanical engineering from Ghent University, Ghent, Belgium, in 2009 and 2013, respectively.

$\mathrm{He}$ is currently working in the Department of Electrical Energy, Systems and Automation, Ghent University, as a Postdoctoral Research Assistant. His research interests include the design and control of electrical drives.

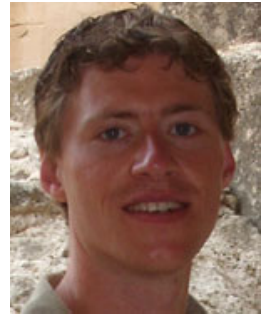

Frederik De Belie (M'05) was born in Belgium in 1979. He received the Master's and Ph.D. degrees in electromechanical engineering from Ghent University, Ghent, Belgium, in 2002 and 2010, respectively.

$\mathrm{He}$ is currently a Postdoctoral Assistant in the Electrical Energy, Systems and Automation Department, Ghent University. His current research interests include modeling theory and controlsystem theory applied to electrical drives, in machines. particular, self-sensing control of synchronous

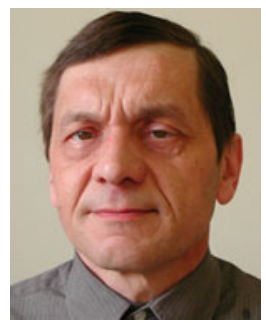

Jan Melkebeek (SM'84) was born in Ghent, Belgium, on February 20, 1952. He received the "Ingenieur" degree in electrical and mechanical engineering and the Doctoral degree in applied sciences from the University of Ghent, Ghent, Belgium, in 1975 and 1980, respectively, and the "Doctor Habilitus" degree in electrical and electronic power technology, in 1986.

Since 1987, he has been a Professor of electrical engineering with the University of Ghent, where he is the Head of the Department of Electrical Power Engineering, Systems and Automation and the Director of the Electrical Energy Laboratory.

Prof. Melkebeek is a Fellow of the Institution of Engineering and Technology, U.K. He served as the President of the IEEE Benelux Industry Applications Society (IAS) and Power Electronics Society (IAS-PELS) joint chapter from 2002 to 2003 and is a long-time member of the IEEEIAS Electric Machines Committee, the IEEE-IAS Electric Drives Committee, and of the IEEE Power Engineering Society Machine Theory Subcommittee.

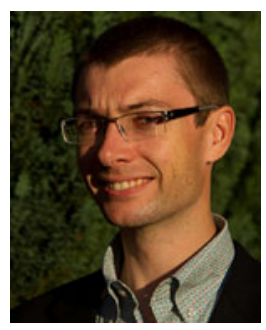

Peter Sergeant (M'12) received the M.Sc. degree in electromechanical engineering in 2001 and the Ph.D. degree in engineering sciences in 2006 from the University of Ghent, Ghent, Belgium.

In 2001, he became a Researcher in the Electrical Energy Laboratory, University of Ghent. He became a Postdoctoral Researcher with the University of Ghent in 2006 (Postdoctoral Fellow of the Research Foundation-Flanders) and with Ghent University College in 2008. Since 2012, he has been an Associate Professor with the University of Ghent. His current research interests include numerical methods in combination with optimization techniques to design nonlinear electromagnetic systems, in particular, electrical machines for sustainable energy applications. 